\title{
DESENVOLVIMENTO INICIAL DE PROFESSORES NO CENTRO DE LÍNGUAS DA UNESP-ASSIS
}

\author{
Edson Luis Rezende Junior ${ }^{1}$ \\ ${ }^{1}$ Mestrando em Educação pelo programa de Pós-Graduação em Educação da Universidade Estadual Paulista (UNESP) \\ - Faculdade de Ciências e Tecnologia de Presidente Prudente. E-mail: edjuuniior@gmail.com. Financiamento: CAPES
}

\begin{abstract}
RESUMO
Apresentamos neste trabalho a extensão universitária como fruto de uma ação de políticas públicas de incentivo ao ensino/aprendizagem de línguas estrangeiras que permite uma aproximação do professor em formação ao seu campo de trabalho, sala de aula. Uma vez que, o mesmo é inserido num contexto que lhe permite construir experiências como docente, ao dar aula da língua estrangeira estudada por ele, sob a supervisão de professores formadores de professores. Assim, nosso objetivo é analisar os relatórios escritos pelos alunos/professores participantes do projeto Centro de Línguas e Desenvolvimento de Professores (CLDP), localizado na Unesp-Assis, com o intuito de observar como se desenvolveu suas experiências e qual a contribuição dada à sua formação como professor de língua estrangeira. Por fim, buscaremos também ressaltar a importância da criação de terceiros espaços para a formação integral do futuro professor.
\end{abstract}

Palavras - chave: Formação de professores; Centro de Línguas; Língua Estrangeira; Extensão Universitária; ensino/aprendizagem.

\section{INITIAL DEVELOPMENT OF TEACHERS IN THE CENTER OF LANGUAGES UNESP-ASSIS}

\begin{abstract}
We present in this work the university extension as the result of an action of public policies of incentive to the teaching / learning of foreign languages that allows an approach of the teacher in formation to its field of work, classroom. Once, it is inserted in a context that allows him to construct experiences as a teacher, when teaching the foreign language studied by him, under the supervision of teacher-training teachers. Our objective is to analyze the reports written by the students / professors participating in the Center for Language and Teacher Development (CLDP), located at Unesp-Assis, in order to observe how their experiences were developed and what contribution their training as a foreign language teacher. Finally, we will also highlight the importance of creating third spaces for the integral formation of the future teacher.

Keysword: Teacher training; Language Center; Foreign language; University Extension; teaching /
\end{abstract} learning. 


\section{INTRODUÇÃO}

Para compreendermos a formação dos centros de línguas como projetos de extensão nos faz necessário primeiramente olhar para a história da extensão universitária em contexto nacional. Pois, nos documentos norteadores da educação brasileira tal termo aparecerá pela primeira vez, somente, na LDB de 1961 (lei de diretrizes e bases da educação nacional) em seu artigo sessenta e nove (69) ao mencionar que "nos estabelecimentos de ensino superior podem ser ministrados cursos de especialização, aperfeiçoamento e extensão... " (BRASIL, 1961, s/p).

Após essa data, percebemos que a LDB de 1971 retira o termo de seus escritos voltando a aparecer novamente, apenas, na Constituição Federal de 1988, no terceiro (III) capítulo, artigo duzentos e sete (207), ao mencionar que "as universidades [...] obedecerão ao princípio de indissociabilidade entre ensino, pesquisa e extensão". Portanto, a partir dessa data a extensão apresenta-se como a conhecemos hoje, parte obrigatória da universidade pública, e ganha espaço dentro do contexto educacional nacional.

Desta maneira, em 1996 a lei 9394 desempenha um importante papel dentro das políticas públicas acerca da extensão universitária, uma vez que, por um lado, retoma a ideia expressa em 1961, na qual a extensão é um curso a ser ofertado pela universidade e, por outro lado, utiliza-se da ideia da constituição ampliando a extensão para parte integral, indissociável, da universidade.

Assim, essa lei, ao discutir as finalidades do ensino superior, artigo quarenta e três (43), inciso sétimo (VII) diz que a universidade deve "promover a extensão, aberta à participação da população, visando à difusão das conquistas e benefícios resultantes da criação cultural e da pesquisa científica e tecnológica geradas na instituição" (BRASIL, 1996, s/p.).

Logo, a lei 9394/96, como pudemos observar contribuiu para a construção de uma universidade mais democrática, preocupada com a relação prática-teoria e que busca promover a participação da população em atividades escolares que aproximem a educação superior à educação básica. Portanto, essa concepção de extensão universitária corrobora com a definição de extensão dada pela UNESP em sua resolução no ano de 2012 em seu artigo primeiro (10): "a extensão universitária é um processo educativo, cultural e científico, que se articula ao ensino e à pesquisa de forma indissociável, e que viabiliza a relação transformadora entre a universidade e a sociedade".

Dessa maneira, surge em 2010 na UNESP-Assis o (CLDP) Centro de Línguas e Desenvolvimento de Professores, que em sua formação caracteriza-se como um projeto colaborativo entre o Departamento de Letras Modernas e o Departamento de Educação. Ademais disso, conta com o apoio da (PROEX) Pró-Reitoria de Extensão e da (AREX) Assessoria de Relações Externas da Universidade Estadual Paulista. O projeto busca oferecer um acesso democrático e gratuito às línguas estrangeiras, às culturas, à comunicação intercultural e ao intercâmbio com outros países. As aulas de inglês, espanhol, francês, italiano, alemão, japonês, chinês (mandarim) e português, como língua estrangeira, ocorrem semestralmente e são oferecidas tanto a comunidade interna ao campus, professores, funcionários e alunos, quanto a comunidade externa, desde que maiores de quinze anos.

As aulas são realizadas por graduandos em formação inicial, do curso de Letras. Estes são acompanhados por um grupo de professores da graduação, respectivos docentes de cada língua estrangeira ensinada, e por um professor coordenador pedagógico, vinculado ao departamento de educação. Assim, o diferencial dessa prática está nas orientações e supervisões dadas aos alunos/professores, sendo que, essas ações deixam implícitas o objetivo do Centro de ser um ambiente de desenvolvimento de professores (MIRANDA; CARVALHO; MESSIAS, 2014, p.70).

As autoras destacam ainda o caráter cíclico do projeto, uma vez que, as experiências dos alunos/professores são trazidas das aulas ministradas, passam pelo processo de reflexão compartilhada durante as reuniões de supervisão e retornam em novas ações nas aulas do CLDP (MIRANDA; CARVALHO; MESSIAS, 2014, 2014, p.72). 
Reforçamos também que tal processo cíclico descrito anteriormente vai ao encontro do conceito de formação de professores descrito por Leffa (2008), uma vez que, para esse autor a formação corresponderia a uma preparação mais complexa e que envolvesse a fusão do conhecimento recebido no contexto institucional com o conhecimento experimental e uma reflexão sobre esses dois primeiros tipos de conhecimentos.

[A formação] busca a reflexão e o motivo por que uma ação é feita da maneira que é feita. Há, assim, uma preocupação com o embasamento teórico que subjaz à atividade do professor. Enquanto que o treinamento limita-se ao aqui e agora, a formação olha além (LEFFA, 2008, p.355).

Portanto, nosso objetivo neste trabalho é observar, a partir dos relatórios escritos pelos alunos/professores, as contribuições que o Centro proporciona à formação inicial de professores de língua estrangeira.

\section{METODOLOGIA}

Como metodologia deste trabalho optamos por desenvolver uma análise dos relatórios produzidos pelos alunos/professores do Centro de Línguas. Os relatórios analisados correspondem as atividades desenvolvidas no ano de 2016 e 2017. Sendo que, ao término de cada semestre os discentes devem elaborar um relato escrito de como foram as aulas, métodos adotados, instrumentos avaliativos, principais dúvidas, pontos positivos e negativos.

A partir desses documentos, buscamos obter um resultado mais fiel a realidade da sala de aula, uma vez que, o aluno/professor possui liberdade para relatar como foi o seu semestre sem se preocupar com possíveis avaliações. Portanto, adotamos o paradigma emancipador descrito em Telles (2002), de modo que, pesquisador e professor estabelecem uma relação de parceria na construção dos sentidos, assim, "[a] relação pesquisador e professor não é só informar, mas produzir a independência e desenvolver a capacidade de reflexão deste último" (TELLES, 2002, p.97).

\section{ANÁLISES DOS RELATÓRIOS (RESULTADOS)}

A partir da leitura dos relatórios optamos por extrair excertos que corroborassem com nosso objetivo, ou seja, que apresentassem segundo os participantes do Centro de Línguas à contribuição dada pelo projeto à sua formação inicial. Ressaltamos que nossa concepção de formação do professor de línguas estrangeiras deve englobar um conhecimento linguístico e outro metodológico acerca da língua que ensina (LEFFA, 2008).

Para isso, algumas ações devem ser previstas e surge a necessidade de que o professor organize suas aulas a partir de um planejamento prévio ao encontro, pense no uso de diferentes recursos e no uso da língua alvo durante o maior tempo da aula.

Era muito gostoso conseguir planejar aulas diferentes e conseguir aplica-las (ARQUIVO PESSOAL RELATÓRIO DE ALUNO-PROFESSOR, 2016).

Ao elaborarmos nossas aulas, pensamos em propor atividades em que língua e sociedade fossem indissociáveis, trazendo, desse modo, algo que proporcionasse aos alunos um contato mais concreto com a língua francesa. Para isso, lançamos mão do uso da tecnologia a favor do ensino de língua estrangeira (ARQUIVO PESSOAL RELATÓRIO DE ALUNO-PROFESSOR, 2016).

Minha estratégia [para intensificar as aulas] foi falar alemão durante toda a aula na medida do possível, para que os alunos pudessem treinar a audição constantemente (ARQUIVO PESSOAL RELATÓRIO DE ALUNO-PROFESSOR, 2016).

Observamos também nos relatos analisados que os alunos expressam como uma das maiores dificuldades a elaboração de materiais para suas aulas. Este fato, pode ser compreendido 
por ser um dos princípios do Centro de Línguas proporcionar aos graduandos a autonomia em sala de aula. Desse modo, inicialmente há as orientações pedagógicas realizadas com todo o grupo de alunos/professores para posteriormente ocorrerem as supervisões em cada língua estrangeira.

Assim, esperamos que o aluno ganhe confiança e investigue diferentes recursos, estratégias e métodos para as aulas de língua estrangeira, em outras palavras, o aluno/professor passa a ser um pesquisador de seu fazer docente.

Comecei dando as primeiras aulas com material não muito preparado e confesso ter ficado nervosa. É muito tenso ter 20 pares de olhos esperando seu próximo passo enquanto você está sozinha na frente deles (ARQUIVO PESSOAL RELATÓRIO DE ALUNOPROFESSOR, 2017).

\begin{abstract}
Durante as aulas percebi que há necessidade de mais preparação da minha parte em relação à oralidade, pois busco falar a todo instante em espanhol, e notei dificuldade em vários aspectos, porém, esta experiência proporciona o contato constante com a língua estrangeira, o que nos exige mais estudo, reflexão e compromisso com ela [...] (ARQUIVO PESSOAL RELATÓRIO DE ALUNO-PROFESSOR, 2017).
\end{abstract}

No começo senti muita dificuldade em preparar materiais didáticos, por onde começar e a maneira de abordar determinado assunto, e algumas vezes também o nervosismo me atrapalhava, me fazendo travar e cometer alguns erros na língua em questão (ARQUIVO PESSOAL RELATÓRIO DE ALUNO-PROFESSOR, 2016).

Nos excertos podemos perceber que esse "despreparo" inicial acarreta num maior nervosismo por parte do aluno/professor. Seja por perceber-se professor e ter "20 pares de olhos te observando", ou na percepção de que "precisa de mais estudo", e/ou até mesmo "travando e errando na língua alvo". Essas percepções vão ao encontro do que Pedra e Nodari (2015) questionam acerca da prática e da teoria estarem lado a lado durante a formação inicial de professores. Pois, ao estabelecerem esse primeiro contato com seu futuro campo de trabalho, a sala de aula, os graduandos passam por um processo de reflexão acerca de sua identidade profissional, sua prática e sua formação.

Segundo as ideias de Leffa (2008) acerca da formação, podemos dizer que, os professores iniciantes ao participarem do Centro de Línguas buscam refletir as razões pelas quais tal ação é feita, seja ao preparar o material ou o seu plano de aula. Logo, “[...] aprender a ser professor não decorre de uma acumulação de cursos, de conhecimentos ou de técnicas, mas de um trabalho de reflexividade crítica sobre as práticas e de reconstrução permanente de uma identidade pessoal e profissional" (BORGES, 2014, p. 42).

Desse modo, buscamos com a inclusão dos alunos nas aulas de língua estrangeira uma formação inicial de docentes, na qual, segundo Borges (2014), o conhecimento acadêmico constitua uma parte das ações do professor, coexistindo e interpenetrando-se com o conhecimento experiencial, pessoal e profissional (saberes práticos e teoria implícitas).

Por fim, para alguns alunos/professores o Centro de Línguas configura-se como um espaço para a criação do habitus professoral (SILVA, 2011), cuja, a participação no projeto torna-se uma chance de experenciar ser professor antes do término do curso. Já para outros, essa oportunidade é vista como um complemento necessário à graduação por suas características de extensão universitária, não só como um projeto no campus, mas, principalmente como uma ponte entre o meio acadêmico e o mercado de trabalho.

Acredito que o centro de línguas vem oferecendo apoio adequado aos professores e sobretudo proporcionando uma valiosa experiência acadêmica e profissional para aqueles que têm interesse pelo ramo da licenciatura de línguas estrangeiras (ARQUIVO PESSOAL RELATÓRIO DE ALUNO-PROFESSOR, 2016).

O CLDP me proporcionou a minha primeira experiência como professora, creio que como estudante de licenciatura do curso de letras isso seja de extrema importância, já que 
nossa prática docente só começa no último ano de graduação (ARQUIVO PESSOAL RELATÓRIO DE ALUNO-PROFESSOR, 2016).

Nesses quase 1 ano e meio dentro do projeto pude tirar como conclusão que o CLDP é uma porta por onde todos os estudantes de letras deveriam ter a oportunidade de entrar, pois como já foi dito, nosso curso possui uma grande defasagem no que diz respeito a área de educação, é de extrema importância que o estudante de licenciatura comece suas práticas docentes o mais rápido possível [...] (ARQUIVO PESSOAL RELATÓRIO DE ALUNO-PROFESSOR, 2017).

O Centro de Línguas proporciona a um futuro docente a capacidade de se reconhecer como professor, pois é por meio desse que nós futuros professores temos um contato mais direto com a sala de aula e uma forma de aprimorar os nossos conhecimentos e a realização das nossas futuras sequências didáticas para aplicarmos nas salas de aula (ARQUIVO PESSOAL RELATÓRIO DE ALUNO-PROFESSOR, 2016).

Portanto, concordamos com Nóvoa (2006) que há um déficit na formação de professores e na reflexão das práticas formativas. Sendo, este um dos objetivos do Centro de Línguas, ao proporcionar um movimento cíclico de ação-reflexão-ação, contudo, espera-se que haja um maior espaço nos currículos de Letras para tais práticas e que mais alunos participem, ainda na graduação, da experiência de se reconhecer como professores (as).

\section{DISCUSSÃO}

Como discussão desse trabalho trazemos o segundo desafio proposto por Nóvoa (2006) ao dialogar sobre os desafios do professor contemporâneo:

O segundo desafio é a formação mais centrada nas práticas e na análise das práticas. A formação do professor é, por vezes, excessivamente teórica, outras vezes excessivamente metodológica, mas há um déficit de práticas, de refletir sobre as práticas, de trabalhar sobre as práticas, de saber como fazer (NÓVOA, 2006, p. 14).

$\mathrm{O}$ autor ainda menciona que muitos jovens professores saem das universidades com a cabeça cheia de livros, teorias, teses e autores e não sabem muito bem o que fazer com tudo isso. Assim, ao observarmos as diferentes contribuições que o projeto de extensão Centro de Línguas proporciona aos alunos, tanto na formação profissional quanto em práticas profissionais em sala de aula, nos questionamos sobre a necessidade de se criar mais espaços de formação inicial de docentes.

Tais espaços são denominados, segundo Zeichener (2010), como "terceiros espaços", sendo que estes rejeitam binaridades, tais como teoria versus prática. Esses espaços também são caracterizados por juntarem o conhecimento prático e o conhecimento acadêmico de forma menos hierárquica. Acreditamos que pensar nesses novos espaços e em políticas de incentivo a formação docente, tais como projetos de inserção de graduandos em contextos híbridos e em salas de aulas com professores mais experientes sejam perspectivas futuras positivas quanto a formação inicial.

\section{CONSIDERAÇÕES FINAIS}

Neste trabalho começamos a discutir um pouco como a extensão universitária consolida-se a partir de ações de políticas públicas. Uma vez que, a mesma passa por diferentes mudanças durante a história da educação brasileira. Desse modo, as leis que regem nosso país, no que tangem a educação, vão assim criando uma definição de extensão universitária que corrobora e constrói uma universidade mais democrática.

Essas mudanças acarretam numa formação mais completa do professor, que passa a refletir mais sobre suas ações e como desenvolvê-las de um modo mais significativo ao seu grupo. Assim, 
projetos como o Centro de Línguas vêm proporcionando grandes contribuições à formação inicial de docentes. A partir dos excertos observamos que os alunos/professores ao iniciarem suas aulas começam a se perceber como professores de língua estrangeira, pois, o contato com o campo de trabalho no qual irão atuar, a sala de aula, Ihes proporciona experiências práticas de sua profissão.

$\mathrm{Na}$ análise dos relatórios percebemos também a necessidade de proporcionar aos futuros professores uma formação mais completa e que vá além do conhecimento linguístico, pois, segundo já citado de Borges (2014, p.42) a "reflexividade crítica sobre as práticas [permite a] reconstrução permanente de uma identidade pessoal e profissional".

Por fim, concordando com as ideias já mencionadas, Nóvoa (2006) reforça que a formação inicial deve estar preocupada na análise dessa prática. Portanto, esperamos que a partir desse trabalho mais universidades motivem-se para criar terceiros espaços de formação docente.

\section{REFERÊNCIAS}

BORGES, M. L. Profissionalidade docente: da prática à práxis. Investigar em Educação - II a Série, Número 2, 2014, p. 39-53.

BRASIL. Lei no 4.024 - fixa as diretrizes e bases da educação nacional, 1961.

Lei no 5.692 - fixa diretrizes e bases para o ensino de $1^{\circ}$ e $2^{\circ}$ graus, e dá outras providências, 1971.

Constituição da República Federativa do Brasil de 1988.

Lei no 9.394 - estabelece as diretrizes e bases da educação nacional, 1996.

(FORPROEX). Indissociabilidade ensino - pesquisa - extensão e a flexibilização curricular: uma visão da extensão. Porto Alegre: UFRGS, Brasília: MEC / SESU, coleção extensão universitária, 2006.

LEFFA, V. J. Aspectos políticos da formação do professor de línguas estrangeiras. In 0 professor de línguas estrangeiras: construindo a profissão. In LEFFA, V.J. O professor de línguas estrangeiras: construindo a profissão. 2ª ed., Pelotas - Educat, 2008, p.353 -376.

MIRANDA, K. R. M.; CARVALHO, K. C. H. P.; MESSIAS, R. A. L. A formação do professor de espanhol no Centro de Línguas da FCL Unesp - Assis: histórias compartilhadas. Anuario brasileño de estudios hispánicos, España, v. I, 2014, p. $67-78$.

NÓVOA, A. Desafios do trabalho do professor no mundo contemporâneo. Palestra concedida ao Sindicato dos professores de São Paulo- SINPRO-SP. 2006.

PEDRA, N. T. S; NODARI, J. I. Ensino de línguas estrangeiras: quando as políticas públicas e as práticas não se encontram. Revista $X$, Dossiê Especial: Experiências do PIBID na formação inicial e continuada de professores de línguas estrangeira, v.1, 2015, p.1 - 15.

RESOLUÇÃO UNESP. Minuta: proposta de criação do subprograma "centros de línguas da Unesp". 2015.

. Dispõe sobre o Regimento Geral da Extensão Universitária na Unesp. 10 p; 2012. 
SILVA, Marilda da. Habitus professoral e habitus estudantil: uma proposição acerca da formação de professores. Educação em Revista - Belo Horizonte, v.27, n.03, 2011, p.335-360.

TELLES, J.A. "É pesquisa, é? Ah, não quero não, bem!" Sobre pesquisa acadêmica e sua relação com a prática do professor de línguas. Linguagem e ensino, 2002, p.91-116.

ZEICHNER, K. Repensando as conexões entre a formação na universidade e as experiências de campo na formação de professores em faculdades e universidades. Educação, Santa Maria, v. 35, n.3, 2010, p. 479-5004. 